\title{
APPLETS EM AMBIENTES DE GEOMETRIA DINÂMICA: AÇÕES PARA A FORMAÇÃO DE PROFESSORES DE MATEMÁTICA
}

\author{
Gilmara Teixeira Barcelos, PGIE/UFRGS, IF Fluminense Campus Campos-Centro \\ gilmarab@iff.edu.br \\ Silvia Cristina Freitas Batista, PGIE/UFRGS, IF Fluminense Campus Campos-Centro \\ silviac@iff.edu.br \\ Patricia Alejandra Behar, NUTED-PGIE/UFRGS \\ patricia.behar@ufrgs.br \\ Liliana Maria Passerino, PGIE/UFRGS \\ liliana@cinted.ufrgs.br
}

\section{RESUMO}

$\mathrm{Na}$ Matemática, os applets, em geral, permitem investigar, levantar e testar conjecturas e, assim, construir conhecimentos. Neste artigo destaca-se a importância da elaboração/modificação de applets, em ambientes de Geometria Dinâmica, desde a formação inicial de professores de Matemática. Em sentido mais amplo, defende-se que a formação inicial destes professores deve contemplar disciplinas relacionadas ao uso pedagógico das tecnologias digitais. Para tanto, relatam-se ações promovidas na disciplina Educação Matemática e Tecnologias (EMTs) e descreve-se o processo de elaboração/modificação de applets no GeoGebra (ambiente de Geometria Dinâmica). Finalizando, analisam-se dados de uma pesquisa qualitativa realizada com alunos da disciplina EMTs. A referida análise sinalizou que o uso e a elaboração/modificação de applets são importantes para a aprendizagem matemática.

Palavras-chave: Geometria Dinâmica, Applet, Formação de Professores de Matemática.

\section{APPLETS IN DYNAMIC GEOMETRY ENVIRONMENTS: ACTIONS FOR MATHEMATICS TEACHER EDUCATION}

Applets, in Mathematics learning, allow the user to investigate, make and test conjectures, which results in knowledge construction. This article emphasizes the importance of elaborating and modifying applets in Dynamic Geometry environments by Mathematics teachers. In a broader sense, it is argued that the initial teacher education should include disciplines related to the pedagogical use of digital technologies. In this context, we report the actions promoted in the discipline "Mathematics Education and Technology" and describe the process of elaborating/modifying the GeoGebra applets (Dynamic Geometry environment). Finally, we analyze data from a qualitative research conducted with students of the discipline "Mathematics Education and Technology". This analysis indicated that the use and elaborating/modifying of applets are important for learning Mathematics.

Keywords: Dynamic Geometry, Applet, Mathematics Teacher Education. 


\section{Introdução}

O professor é o responsável por organizar e estruturar o ambiente educativo, assim como propiciar oportunidades de aprendizagem para os alunos. Como os saberes docentes são situados, isto é, construídos e utilizados em função de uma situação específica de trabalho (Tardif, 2007), a possibilidade de elaborar recursos pedagógicos, que atendam a particularidades, é relevante para o processo de ensino e aprendizagem. Nesse sentido, é importante considerar o uso de tecnologias digitais para fins pedagógicos (UNESCO, 2009). É necessário, inclusive, que os professores tenham oportunidades de capacitação para tornarem-se autores de recursos pedagógicos digitais (Tarouco et al., 2006), afinal desempenham papel de destaque na integração da escola na cultura digital ${ }^{1}$.

Os ambientes de Geometria Dinâmica podem contribuir para a elaboração de recursos pedagógicos digitais. Estes ambientes permitem a elaboração de construções eletrônicas, nas quais os elementos básicos podem ser movimentados na tela do computador, sem alterar as posições relativas entre estes elementos e os objetos construídos a partir deles (Braviano; Rodrigues, 2002). Tais construções são interativas e permitem testar conjecturas, analisando exemplos e contra-exemplos, que podem ser gerados facilmente. Tudo isso faz dos ambientes de Geometria Dinâmica importantes recursos digitais para aprendizagem. O GeoGebra, o Régua e Compasso $(\operatorname{ReC})$, o Tabulae e o iGeom são ambientes com este fim, todos gratuitos ${ }^{2}$ e com recursos que permitem gerar applets $^{3}$. Esta ação é simples de ser realizada e possibilita contemplar temas a serem abordados e particularidades da prática docente.

Diversas pesquisas têm sido realizadas sobre o uso de applets na aprendizagem matemática (Yerushalmy, 2005; Underwood et al., 2005; Brandão et al., 2006; Lee e Hollebrands, 2006; Gil, 2008; Santos, 2008). O uso de applets permite experimentações e investigações, o que possibilita o estabelecimento de conjecturas sobre determinado conceito e a construção do mesmo, de forma consistente (Santos, 2008). Ao gerar um applet e a sequência didática para uso deste recurso, o professor também constrói conhecimentos, o que contribui para sua prática docente (Santos, 2008). Dessa forma, é importante que o professor de Matemática tenha, por exemplo, oportunidade de aprender a elaborar e modificar applets, utilizando ambientes de Geometria Dinâmica ou outros recursos.

Este artigo tem por objetivo ressaltar a importância da elaboração/modificação de applets em ambientes de Geometria Dinâmica, por professores de Matemática. Os aspectos que o diferem dos trabalhos anteriormente citados são o relato e a análise da elaboração de applets na formação inicial de professores de Matemática. Por meio destes diferenciais, defende-se, a importância do desenvolvimento de recursos pedagógicos, pelo próprio professor, contemplando necessidades do seu contexto.

Para tanto, na seção 2, destaca-se a importância de que o futuro professor, em seu processo de formação, vivencie práticas pedagógicas coerentes com aquelas que se espera que venha a praticar. Na seção 3, relatam-se ações realizadas na disciplina Educação Matemática e Tecnologias (EMTs), da Licenciatura em Matemática do Instituto Federal Fluminense Campus Campos-Centro, destacando o processo de elaboração/modificação de applets no GeoGebra. Na seção 4, analisam-se dados de uma pesquisa qualitativa, por meio de estudo de caso, sobre a importância do uso e da elaboração/modificação de applets gerados no GeoGebra e no ReC. Finalizando, na seção 5, são apresentadas algumas considerações sobre o tema abordado.

\section{Formação inicial de professores: práticas docentes}

Diversos estudos sobre formação de professores têm sido realizados, buscando 
caminhos para melhoria da prática docente (Zeichner, 1993; Perrenoud, 1993; Imbernon, 1994; Nóvoa, 1995; Sacristan e Gomez, 2000; Schön, 2000; Rego e Mello, 2002; Géglio, 2006; Tardif, 2007). Considera-se que a importância destes estudos está, entre outros fatores, na coerência que deve existir entre a formação que ocorre nas licenciaturas e nos cursos de formação continuada e a prática docente esperada do futuro professor.

No parecer CNE/CP 9/2001, que contém as Diretrizes Curriculares Nacionais para a Formação de Professores da Educação Básica, em nível superior, curso de licenciatura, de graduação plena é destacado que:

A preparação do professor tem duas peculiaridades muito especiais: ele aprende a profissão no lugar similar àquele em que vai atuar, porém, numa situação invertida. Isso implica que deve haver coerência entre o que se faz na formação e o que dele se espera como profissional. Além disso, com exceção possível da educação infantil, ele certamente já viveu como aluno a etapa de escolaridade na qual irá atuar como professor (BRASIL, 2002a, p. 30, grifo nosso).

O princípio da simetria invertida contribui para a compreensão de que as vivências dos futuros professores, como alunos em sua formação docente, é constitutiva do papel que exercerá na sua prática docente futura (BRASIL, 2002a). Este fato ressalta a importância de que o futuro professor, enquanto aluno em seu processo de formação, vivencie práticas pedagógicas coerentes com aquelas se espera que venha a praticar (BRASIL, 2002a). É importante que o discurso dos professores dos cursos de formação seja coerente com suas práticas. Isto não implica em tornar as situações de aprendizagem dos cursos de formação, mecanicamente análogas, às situações de aprendizagem de crianças e jovens (BRASIL, 2002a).

Segundo Rego e Melo (2002), já há hipóteses plausíveis sobre a direção das transformações que podem orientar novas políticas de formação docente. Estas hipóteses sinalizam a preocupação em contemplar aspectos relacionados à simetria invertida. Uma destas hipóteses reforça a importância do que é realizado na Licenciatura em Matemática do IF Fluminense, em particular na disciplina EMTs:

É mais urgente incorporar a tecnologia da informação nos currículos de formação docente do que nos currículos da educação primária e secundária. As novas tecnologias devem ser usadas para apoiar a aprendizagem do professor, possibilitando que ele avalie com base na sua própria aprendizagem, a riqueza que as tecnologias da informação podem aportar ao ensino (Rego; Melo, 2002, p. 20).

Em particular, com relação à formação de professores de Matemática, o resultado de um estudo de currículos, promovido com uma amostra representativa, composta de 31 cursos de Licenciatura em Matemática no Brasil, sinaliza que ainda há muito a avançar (Gatti; Nunes, 2009). Por meio da análise de currículos e ementas foi verificado que apenas 29\% das Licenciaturas em Matemática brasileiras possuem disciplinas que contemplam, claramente, o uso da informática para educação (Gatti; Nunes, 2009).

Neste contexto, destaca-se que desde 2004 há na matriz curricular da Licenciatura em Matemática do IF Fluminense Campus Campos-Centro, a disciplina EMTs ${ }^{4}$. O objetivo geral da mesma é incentivar o uso consciente e crítico de tecnologias digitais, como recurso pedagógico para aprendizagem matemática. $\mathrm{Na}$ seção seguinte, descrevem-se, resumidamente, ações realizadas nesta disciplina.

\section{Educação Matemática e Tecnologias}

A disciplina EMTs possui carga horária de três horas/aula semanais e é oferecida no primeiro período. Com as ações realizadas na mesma busca-se cumprir as diretrizes das Licenciaturas em Matemática, no que diz respeito à competência "capacidade de 
compreender, criticar e utilizar novas idéias e tecnologias para a resolução de problemas" (BRASIL, 2002b, p.3). Além disso, a disciplina visa contemplar as seguintes temáticas: i) Conhecimentos básicos em Informática; ii) Tecnologias de Informação e Comunicação - Educação - Sociedade; iii) Utilização e avaliação de softwares educacionais voltados para o ensino e aprendizagem de Matemática; iv) Internet e seus recursos; v) Matemática e TICs aplicadas ao Ensino Fundamental e Médio (Barcelos, 2004).

As atividades desenvolvidas dão suporte às demais disciplinas do curso e fundamentam práticas docentes dos professores. Inicialmente, solicita-se o preenchimento de um questionário, por meio do qual se investiga o nível de inclusão digital dos mesmos. Outro questionário é respondido ao final do período. Ao preencher os questionários, cada professor em formação, entre outras coisas, avalia o seu grau de conhecimento com relação à realização de atividades básicas utilizando tecnologias digitais. Percebe-se, pela análise das respostas, que as ações desenvolvidas têm contribuído para o uso destas tecnologias na aprendizagem matemática.

$\mathrm{Na}$ disciplina, são realizadas atividades diversas, fundamentadas na teoria sóciointeracionista, tais como: i) leituras e discussão de textos, nas quais os grupos de alunos utilizam software de apresentação para apresentar suas análises; ii) estudo de softwares educacionais por meio de atividades que possibilitam o reconhecimento das funcionalidades destes e de atividades que visam à construção de conhecimentos matemáticos; iii) avaliação de softwares, buscando favorecer o conhecimento de critérios importantes a serem avaliados em softwares educacionais de Matemática; iv) elaboração de atividades de investigação, utilizando um dos softwares estudados (dentre os quais o Geogebra e o $R e C$ ); v) análise de sites relacionados à aprendizagem matemática; vi) elaboração/modificação de applets utilizando o Geogebra e o ReC.

Há um momento de apresentação dos applets elaborados, com análise dos mesmos pelos colegas da turma, a partir do referencial teórico estudado. Os principais aspectos discutidos são o objetivo e o design pedagógico ${ }^{5}$ (fatores gráficos e pedagógicos) dos applets. As orientações para elaboração/modificação dos applets são descritas a seguir.

\subsection{Elaboração e modificação de applets no GeoGebra}

As orientações que os alunos da disciplina EMTs recebem em relação à elaboração/modificação de applets no GeoGebra (no $\operatorname{ReC}$ o processo é semelhante) podem despertar o interesse de outros professores pelas referidas ações. Nesse sentido, apresentam-se, brevemente, tais orientações.

No menu principal de uma construção do GeoGebra (arquivo.ggb), deve-se clicar em "Arquivo" e, a seguir, pausar o mouse em "Exportar". Nas opções abertas, clica-se em "Planilha Dinâmica como Página WEB (html)..." (Figura 1).

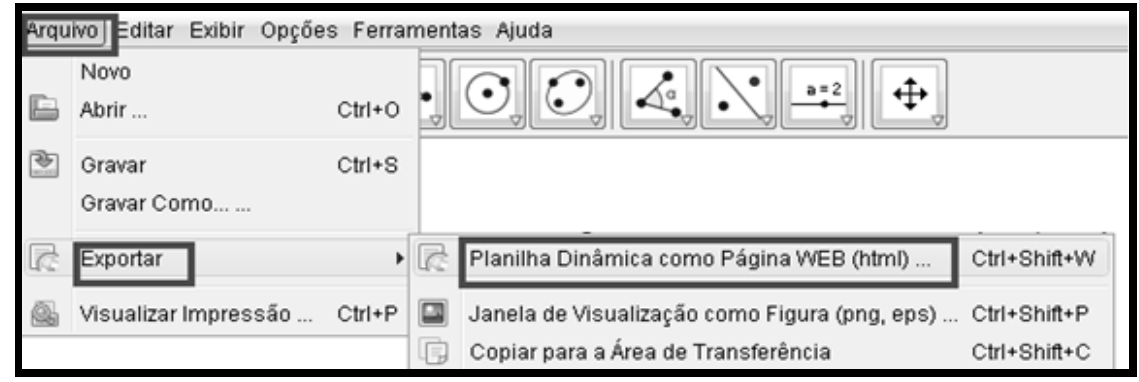

Figura 1. Passos para abertura da janela de exportação

$\mathrm{Na}$ janela de exportação (Figura 2), no campo "Título", escreve-se o nome do applet. Os campos "texto acima da construção" e "texto abaixo da construção" servem para apresentar orientação de uso do applet. 
Ao clicar na aba "Avançado" (Figura 2), podem ser marcadas algumas opções quanto à funcionalidade e à interface do applet. Após marcar as opções desejadas, clicase em "Exportar". Outra janela será aberta, nessa bastará escolher o local para salvar o arquivo e clicar em "Gravar", é preciso que o arquivo da construção e o arquivo do applet estejam na mesma pasta. Na referida pasta, além dos dois arquivos mencionados, estarão outros seis arquivos gerados, automaticamente, pelo GeoGebra. Após gerar o applet (arquivo .html) este será aberto no navegador Web padrão do computador.

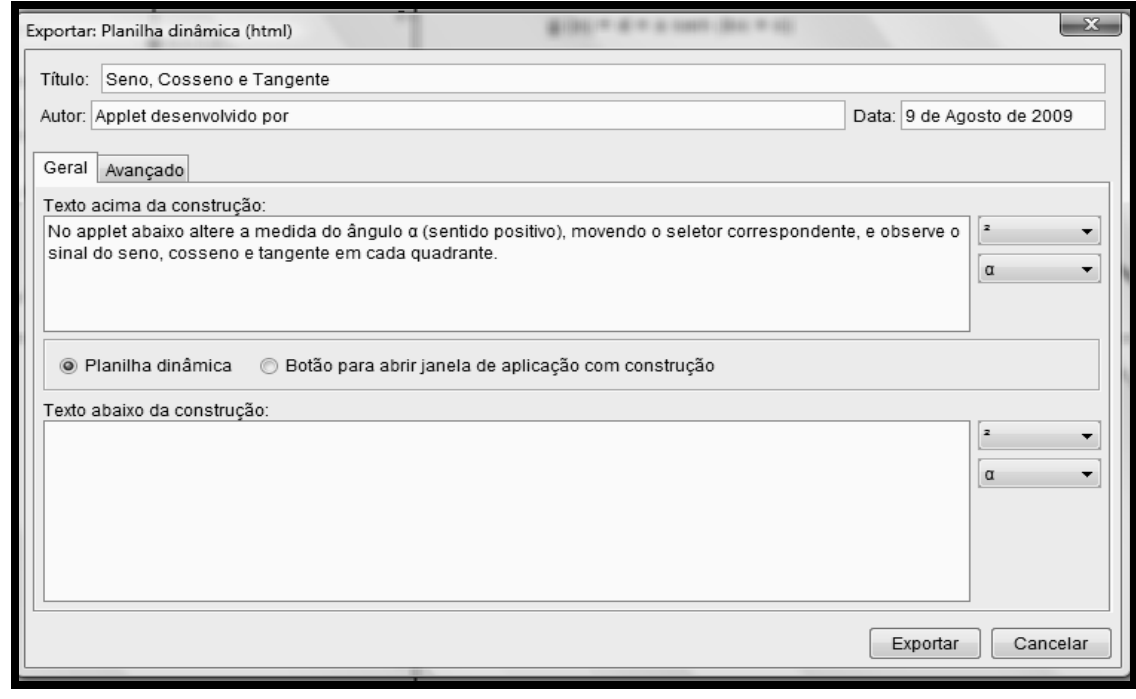

Figura 2. Janela de exportação para planilha dinâmica

$\mathrm{O}$ fato de o applet ser um arquivo com extensão .html, permite que esse seja aberto em computadores nos quais o GeoGebra não está instalado, bastando ter um navegador Web. Isto é importante, pois, em geral, a instalação de softwares nas escolas, mesmo gratuitos, não é imediata, requer permissão do administrador. Além disso, o procedimento para gerar um applet no GeoGebra é simples, o que permite que professores construam seus próprios applets, possuindo apenas conhecimentos básicos de Informática e conhecimentos matemáticos sobre o tema abordado.

Para fazer modificações no applet criado, basta abrir a construção (arquivo .ggb), fazer as alterações necessárias e salvá-las. Estas modificações aparecerão, automaticamente, quando o applet for aberto, uma vez que o mesmo está associado à construção feita no GeoGebra. No applet é possível realizar ações diversas, mas, ao fechá-lo esse retornará ao seu estado original, ou seja, não é possível salvar modificações, diretamente, no próprio applet. Uma forma de salvar as modificações é dar dois cliques, com o botão esquerdo do mouse, na tela do applet. Com este procedimento será aberta a janela de configuração, na qual é possível fazer modificações e salvar a construção (deve-se manter o nome do arquivo da construção que deu origem ao applet). Esta forma de salvar somente pode ser usada, se, ao gerar o applet, o desenvolvedor ativar a funcionalidade "Um clique duplo sobre a janela de visualização abre a janela de configuração".

A partir de um applet do GeoGebra, encontrado na Internet ${ }^{6}$, também é possível salvar o arquivo da construção que o gerou. Esta ação é possível se o desenvolvedor disponibilizar o menu principal no applet ou quando o clique duplo sobre a janela de visualização for permitido. A partir deste arquivo, é possível promover modificações e gerar um novo applet, que seja mais adequado à realidade do usuário. No arquivo da construção, promovem-se as modificações necessárias e, para gerar o applet dessa nova construção, é necessário que se faça todo o processo descrito anteriormente. 
Para modificar um applet desenvolvido no $\operatorname{Re} C$, encontrado na Internet, também é necessário salvar a construção que o gerou. No entanto, a obtenção do arquivo da construção do $\operatorname{ReC}$ não é realizada a partir do próprio applet, como no GeoGebra. Neste caso, o arquivo da construção (arquivo.zir) deve ser disponibilizado para download, pelo desenvolvedor.

\section{Estudo de caso: importância da elaboração/modificação de applets}

A pesquisa realizada foi de cunho qualitativo, por meio de estudo de caso, na turma de $1^{\circ}$ período da Licenciatura em Matemática. As técnicas de coleta de dados foram, essencialmente, observação participante e questionário.

No primeiro semestre de 2009, 16 professores em formação, alunos da disciplina EMTs, foram observados durante a elaboração/modificação de applets na disciplina EMTs. Após elaborarem/modificarem applets no Geogebra e no $\operatorname{ReC}$, responderam a um questionário. É importante ressaltar que a maioria (aproximadamente 80\%) desses alunos iniciou o uso de tecnologias digitais na referida disciplina. As dificuldades iniciais com relação às funcionalidades básicas destas tecnologias, reduzidas ao longo da disciplina, foram consideradas pelos professores em formação, ao responderem o questionário. Esta afirmação é feita baseada no discurso oral dos professores em formação no momento em que preenchiam o questionário.

O questionário continha oito perguntas semiabertas ${ }^{7}$ cujo objetivo era levantar dados sobre a importância do uso e da elaboração/modificação de applets gerados no GeoGebra e no $\operatorname{ReC}$, por professores em formação. As respostas foram analisadas e as consideradas mais significativas são comentadas a seguir.

Com relação ao uso de applets, todos afirmaram que esse favorece a construção de conhecimentos matemáticos. Destaca-se um comentário registrado.

Porque é uma forma de ver conteúdos de matemática, que antes só ficavam no papel, em movimento, de forma dinâmica e possibilitando ao aluno visualizar (Professor em formação 8).

A visão desse participante está coerente com a de Santos (2008), mencionada na introdução deste artigo, assim como com a de Yerushalmy (2005), quando este afirma que figuras em papel, estáticas, limitam a capacidade de estabelecer conjecturas.

Quanto à importância da elaboração/modificação de applets em ambientes de Geometria Dinâmica, pelo professor, apenas um participante respondeu "Depende", todos os demais responderam "Sim". O que respondeu "Depende", não justificou. Os que responderam "Sim" destacaram, de maneira geral, que os applets favorecem a construção do conhecimento e, assim, o professor precisa apropriar-se do processo de elaboração/modificação, para levar em consideração as características particulares de seu contexto. Esta visão está coerente com a posição de Tardif (2007), quando este defende que os saberes docentes são situados.

As respostas ao questionamento sobre o nível de dificuldade em elaborar ou modificar applets no GeoGebra e no $R e C$ foram diversificadas (Tabela 1). Os professores em formação que consideraram "Moderado" e "Dificil", de maneira geral, afirmaram que não tinham, inicialmente, muitas habilidades para usar as tecnologias digitais mas evoluíram ao longo da disciplina, porém não a ponto de considerar o processo fácil. Tais justificativas sinalizam uma reflexão sobre a ação ${ }^{8}$, pois estes professores em formação, conscientemente, analisaram e avaliaram as ações desenvolvidas na disciplina EMTs, o que permite a compreensão e reconstrução de suas práticas (GÓMEZ, 1995).

Tabela 1. Nível de dificuldade em elaborar/modificar applets

\begin{tabular}{|c|c|c|c|c|}
\hline Muito Fácil & Fácil & Moderado & Difícil & Muito Difícil \\
\hline 2 & 4 & 8 & 2 & 0 \\
\hline
\end{tabular}


A maioria dos alunos considerou mais fácil (Tabela 2) a elaboração/modificação de applets no GeoGebra do que no $R e C$. Este fato foi justificado apenas pela não necessidade de colocar mais um arquivo junto à construção do $\operatorname{Re} C^{9}$. Os que consideraram "Indiferente" ressaltaram que as ferramentas dos dois ambientes são muito semelhantes.

Tabela 2. Comparação - ReC e GeoGebra
\begin{tabular}{|c|c|c|}
\hline $\operatorname{ReC}$ & GeoGebra & Indiferente \\
\hline 1 & 13 & 2 \\
\hline
\end{tabular}

Em relação ao papel do professor durante a utilização dos applets, aproximadamente $81 \%$ dos professores em formação consideraram "Muito Importante" e os demais "Importante". Este resultado evidencia o que é defendido por Rego e Melo (2002), quando afirmam que é importante incorporar tecnologias digitais desde a formação inicial de professores. Apresenta-se um comentário registrado.

O papel do professor é muito importante, pois possibilita ao aluno enxergar

alguns pontos que ele não consegue ver (Professor em formação 4).

Os índices e comentários sinalizaram o entendimento de que o uso de recursos digitais não diminui o papel do professor, que deve, entre outras ações, incentivar questionamentos, socialização de idéias e análises críticas de resultados. Moysés (2007) afirma que na educação escolar, o professor é o sujeito mais experiente que, por meio de perguntas-guia, exemplos e demonstrações, realiza intervenções que podem ajudar o aluno a realizar uma tarefa.

Quatorze professores em formação ressaltaram que o esforço e todas as dificuldades na elaboração/modificação e uso de applets são compensados com o resultado positivo obtido. O professor em formação 8 afirmou que:

Sim. Porque é muito legal ver em movimento uma propriedade que antes eu só via no papel e através do applet posso ver de forma dinâmica.

Este comentário ressalta, mais uma vez, a vantagem do uso dos applets, pois a movimentação, possibilitada pelos applets, facilita o estabelecimento de conjecturas. Um professor em formação respondeu que "Depende" da forma como os applets são utilizados, o que é coerente, pois, o recurso por si só não é suficiente. Outro respondeu "Não", mas não justificou.

Quando questionados se, em suas práticas docentes, elaborariam/modificariam e usariam applets, aproximadamente, $87 \%$ dos professores em formação responderam que "Sim", os demais que "Depende". Este resultado retrata que estes professores têm uma postura favorável à criação dos referidos recursos. Fato coerente com a visão de Tardif e Lessard (2007) quando afirmam que o professor precisa tomar decisões com relação à escolha dos meios, aos objetivos pretendidos e à utilização do material adequado, entre outros aspectos. O comentário a seguir, é de um participante que respondeu positivamente.

Porque é uma forma de mostrar construções dinâmicas, já que não é preciso o uso de Internet, o que é ótimo porque infelizmente nem todas as escolas públicas tem acesso a Internet (Professor em formação 8).

Este comentário, novamente, destaca a importância dos applets na aprendizagem matemática. A justificativa dos que responderam "Depende" baseou-se nas carências tecnológicas das escolas brasileiras. Ressalta-se, no entanto, que o uso de applets, por meio de apenas um computador e um projetor multimídia, pode contribuir para o estudo do tema. Estes equipamentos que, atualmente, muitas escolas possuem, podem minimizar o problema em relação à falta de laboratório de informática nas escolas.

De maneira geral, a observação das ações destes professores em formação e a análise dos dados levantados sinalizam que o uso e a elaboração/modificação de applets são importantes para a aprendizagem de Matemática. Tal resultado está, intimamente, 
ligado às ações desenvolvidas na disciplina EMTs, que fundamentaram todo o processo. $\mathrm{O}$ discurso dos professores em formação, durante a elaboração/modificação dos applets e nas demais atividades da disciplina, indica que eles perceberam a coerência entre o foi feito e o que dele se espera na prática docente (simetria invertida).

\section{Considerações Finais}

Ações direcionadas à melhoria da formação de professores de Matemática são essenciais. Considera-se importante, nesse sentido, a inserção das tecnologias digitais como instrumento mediador da aprendizagem, em disciplinas da licenciatura. Tal inserção pode permitir que o professor em formação avalie, com base na sua própria aprendizagem, a riqueza que as tecnologias podem trazer a sua prática docente. Os applets, em particular, possibilitam interatividade, investigações, estabelecimento de conjecturas, entre outras ações, permitindo práticas docentes mais coerentes com o perfil dos alunos das atuais sociedades.

A observação das ações dos professores em formação e a análise das respostas dos questionários fornecem indícios de que o uso e a elaboração/modificação de applets é viável e pode contribuir para a aprendizagem matemática. Estes resultados podem incentivar que tais ações sejam realizadas em outras licenciaturas em Matemática, assim como, em cursos de formação continuada. Além disso, a análise dos resultados pode contribuir para que os professores de Matemática entendam a importância da elaboração e uso de recursos interativos para a aprendizagem.

Destaca-se que, embora o processo de gerar applets em ambiente de Geometria Dinâmica seja simples, a elaboração da construção (passo anterior ao applet) requer atenção. Nesta elaboração, devem ser considerados os cuidados necessários a todo objeto educacional digital (fatores gráficos, perfil do usuário, conteúdo abordado, interatividade, entre outros). Nesse sentido, uma fundamentação teórica relacionada ao uso de tecnologias digitais na educação, como a realizada na disciplina EMTs, é fundamental.

Neste estudo, destaca-se a importância do desenvolvimento de applets pelo próprio professor, no entanto, é importante ressaltar que existem diversos destes recursos disponíveis na Internet, de boa qualidade. Cabe a cada professor, de acordo com seu contexto educacional, optar por selecionar, adaptar ou desenvolver o recurso pedagógico que melhor atenda aos seus objetivos.

\section{Notas de Texto}

1 A Cultura Digital é a cultura de rede, a cibercultura que sintetiza a relação entre sociedade contemporânea e Tecnologias da Informação (Hoffmann; Fagundes, 2008).

${ }^{2}$ Disponíveis, respectivamente, em <http://www.geogebra.at/>, $<$ http://www.ntegravatai.relrs.g12.br/progr/ReC/>; $\quad<$ http://tabulae.net/pcm/>; $<$ http://www.matematica.br/igeom/>

${ }^{3}$ Applets (applets Java) são programas desenvolvidos em linguagem de programação Java®, que podem ser incluídos em códigos HTML (Deitel, H.; Deitel, P. 2003). Estes recursos, em geral, visam adicionar interatividade a aplicações Web.

${ }^{4}$ Ministrada por uma das autoras deste artigo.

${ }^{5} \mathrm{O}$ design pedagógico preocupa-se com as ações futuras do usuário sobre o produto, as quais devem possibilitar posturas críticas, investigativas e autônomas (Torrezzan; Behar, 2009).

6 Recomenda-se entrar em contato com os responsáveis pelo applet, antes de promover modificações em seus arquivos originais, em respeito aos direitos autorais.

${ }^{7}$ As semiabertas são questões que introduzem, por exemplo, o item "outros", dando uma possibilidade de resposta para além das previstas, ou possibilitam a justificativa de uma resposta padronizada.

V. 7 No 3, dezembro, 2009 
${ }^{8}$ Reflexão sobre a ação é a análise que o indivíduo realiza, a posteriori, sobre as características e processos da sua própria ação (Gómez, 1995).

${ }^{9}$ Para elaborar um applet no ReC é necessário ter um arquivo executável, que não é gerado, automaticamente, no desenvolvimento do applet.

\section{Referências Bibliográficas}

BARCELOS, G. T. Inovação no sistema de ensino: o uso das Tecnologias de Informação e Comunicação nas licenciaturas em Matemática da Região Sudeste. Campos dos Goytacazes, RJ: Universidade Estadual do Norte Fluminense - UENF, 2004. Dissertação de Mestrado em Ciências de Engenharia.

BRANDÃO, L. O.; ISOTANI, S.; MOURA, J. G. Imergindo a geometria dinâmica em sistemas de educação a distância: iGeom e SAW. Revista Brasileira de Informática na Educação, Sociedade Brasileira de Computação, v. 14, n. 1, p. 41-49, 2006.

BRASIL, MEC- Ministério da Educação - Parecer CNE/CP 9/2001 - Homologado Despacho do Ministro em 17 de Janeiro de 2002. Brasília: Diário Oficial da União de 18 de Janeiro de 2002, Seção 1, p. 31. 2002a Disponível em:<http://portal.mec.gov.br/cne/arquivos/pdf/009.pdf>. Acesso em: 15 out. 2009.

BRASIL, MEC - Ministério da Educação. Parecer CNE/CES 1.302/2001Homologado. Despacho do Ministro em 4/3/2002, publicado no Diário Oficial da União de 5/3/2002. 2002b Disponível em: <http://www.cefetma.br/downloads/desu/mat/LEG.\%20MATEMATICA\%201.pdf>. Acesso em: 20 jun. 2009.

BRAVIANO, R.; RODRIGUES M. H. W. L. Geometria Dinâmica: uma nova Geometria. Revista do Professor de Matemática, São Paulo: Sociedade Brasileira de Matemática, n. 49, p. 22-26, 2002.

DEITEL, H. M; DEITEL, P. J. Java, como programar. Tradução de Carlos Arthur Lang Lisboa. 4. ed. Porto Alegre: Bookman, 2003.

GATTI, B. A.; NUNES, M. M. R. (org.) Formação de professores para o ensino fundamental: estudo de currículos das licenciaturas em pedagogia, língua portuguesa, matemática e ciências biológicas. São Paulo: FCC/DPE, 2009. Disponível

em: http://www.fcc.org.br/pesquisa/publicacoes/textos_fcc/arquivos/1463/arquivoAnexado. pdf. Acesso em: 15 out. 2009.

GÉGLIO, P. C. Questões da formação continuada de professores. São Paulo: AlfaOmega, 2006.

GIL, C. R. Descartes, avances y novedades. In: CONGRESSO NACIONAL INTERNET EN EL AULA, 1., 2008, Barcelona-Espanha: Governo da Espanha. p. 1$4 . \quad$ Disponível em: $<$ http://descartes.cnice.mec.es/heda/difusion/materiales/ia08/Consolacion_Ruiz.pdf > Acesso em: 15 out. 2009.

GÓMEZ, A. P. O Pensamento Prático do Professor. In: NÓVOA, A. (coord.) Os professores e a sua formação. Tradução de Graça Cunha, Cândida Hespanha, Conceição Afonso e José António Sousa Tavares. 2.ed. Lisboa: Dom Quixote, 1995.

HOFFMANN, D.; FAGUNDES, L. C. Cultura Digital na Escola ou Escola na Cultura Digital? Revista Novas Tecnologias na Educação (RENOTE), Porto Alegre. v. 6, p. 1-10, jul. 2008.

IMBERNÓN, F. La formación del professorado. Barcelona: Paidós, 1994. 
LEE, H. S.; HOLLEBRANDS K. F. Students' use of technological features while solving a mathematics problem. Journal of Mathematical Behavior, v. 25, n. 3, p. 252-266, 2006.

MOYSÉS, L. Aplicações de Vygotsky à Educação Matemática. 8. ed. Campinas-SP: Papirus, 2007.

NÓVOA, A. (coord.) Os professores e a sua formação. Tradução de Graça Cunha, Cândida Hespanha, Conceição Afonso e José António Sousa Tavares. 2.ed. Lisboa: Dom Quixote, 1995.

PERRENOUD, P. Práticas pedagógicas, profissão docente e formação: perspectivas sociológicas. Lisboa: Publicações Dom Quixote, 1993.

REGO, T. C.; MELLO, G. N. Formação de professores na América Latina e Caribe: a busca por inovação e eficiência. CONFERÊNCIA REGIONAL FORMAÇÃO DE PROFESSORES NA AMÉRICA LATINA E CARIBE. 2002, Brasília/DF. Anais. Disponível em: $<$ http://www.namodemello.com.br/pdf/escritos/oficio/teresaversaoenviada.pdf $>$. Acesso em: 15 out. 2009.

SACRISTAN, J. G.; GOMEZ A. I. P. Compreender e transformar o ensino. Tradução de Ernani F. da Fonseca Rosa. Porto Alegre: Artmed, 2000.

SANTOS V. C. P. Mathlets: possibilidades e potencialidades para uma abordagem dinâmica e questionadora no ensino de Matemática. Rio de Janeiro, RJ: Universidade Federal do Rio de Janeiro, 2008. Dissertação de Mestrado em Ensino de Matemática.

SCHÖN, D. A. Educando o profissional reflexivo: um novo design para o ensino e a aprendizagem. Tradução de Roberto Cataldo Costa. Porto Alegre: Artmed, 2000.

TARDIF, M. Saberes docentes e formação profissional. 8.ed. Tradução de Francisco Pereira. Petrópolis-RJ: Vozes, 2007.

TARDIF, M.; LESSARD, C. O trabalho docente: elementos para uma teoria da docência de interações humanas. Tradução de João Batista Kreuch. 3. ed. Petrópolis: Vozes, 2007.

TAROUCO, L. M. R., KONRATH, M. L. P., CARVAlHO, M. J. S., AVILA, B. G. Formação de professores para produção e uso de objetos de aprendizagem. Revista Novas Tecnologias na Educação (RENOTE). Porto Alegre, v. 4, n. 1, p. 01 - 10, jul. 2006.

TORREZZAN, C. A. W., BEHAR, P. A. Parâmetros para construção de materiais educacionais digitais do ponto de vista do design pedagógico. In: Behar, P. A. e Colaboradores. Modelos pedagógicos em educação a distância. Porto Alegre: Artmed. p. 33-65, 2009.

UNDERWOOD, J.; HOADLEY, C.; LEE, H. S.; HOLLEBRANDS, K. F.; DIGIANO, C.,; RENNINGER, K. A. IDEA: identifying design principles in educational applets. Educational Technology Research and Development, v. 53, n. 2, p. 99-112, 2005.

UNESCO. Coleção Padrões de competência em TIC para professores: Módulos de Padrões de Competências. Tradução de Cláudia Bentes David. Brasília: UNESCO, 2009. Disponível em: <http://unesdoc.unesco.org/images/0015/001562/156210por.pdf>. Acesso em: 10 ago. 2009.

ZEICHNER, K. M. A formação reflexiva de professores: idéias e práticas. Lisboa: Educa, 1993. 
ro consumes

YERUSHALMY, M. Functions of interactive visual representations in interactive mathematical textbooks. International Journal of Computers for Mathematical Learning, n. 10, p. 217-249, 2005. 